\title{
PUBLICACIONES SERIADAS
}

\author{
SERIAL PUBLICATIONS \\ (iD) Edgar Gutiérrez Gómez ${ }^{*}$ \\ egutierrez@unah.edu.pe \\ ${ }^{1}$ Universidad Nacional Autónoma de Huanta, Ayacucho, Perú
}

*Correspondencia: Edgar Gutiérrez Gómez. Email: egutierrez@unah.edu.pe

El gobierno de turno evalúa la necesidad de producciones científicas en su sector estatal más complejo, la educación. En esa línea se encuentra fomentando incentivos al quehacer académico de la investigación, en especial en las universidades públicas a nivel nacional, después de haber depurado con un proceso de licenciamiento a todas las universidades del Perú. Una de las prerrogativas indispensables es la publicación de artículos en revistas indizadas, haber publicado libros, haber desarrollado ponencias completas en eventos científicos, estar liderando proyectos de investigación entre otras condiciones como requisito para estar inmerso como docentes investigadores. Esta consideración se materializa en el: "Decreto Supremo que aprueba "Disposiciones para la implementación progresiva de la Bonificación Especial para el Docente Investigador" (El Peruano, 2020) En referencia al Decreto Supremo, la Universidad Nacional Autónoma de Huanta, viene promoviendo una serie de investigaciones con el Fondo de Desarrollo Socioeconómico de Camisea- FOCAM, convergiendo en que los resultados retribuyan a las poblaciones vulnerables y en desarrollo. La naturaleza de fundación de las universidades es desarrollar investigaciones científicas como correspondencia a La Ley $\mathrm{N}^{\circ}$ 28451: "Por su parte, las universidades públicas deberán utilizar los recursos del FOCAM para fines de investigación científica y tecnológica". Teniendo en cuenta el ingreso del $10 \%$ en partes iguales para las universidades públicas comprendido en el FOCAM.

En este volumen de la Revista de Investigación Científica de la Universidad Nacional Autónoma de Huanta, presentamos los trabajos de investigadores que apuestan por la sostenibilidad de la revista en el tiempo. Es comprensible la aglomeración de artículos en revistas que se encuentran en repositorios que aprueba CONCYTEC para su evaluación en RENACYT, ahí los investigadores apuestan publicar artículos científicos para evaluarse como investigador. Desde esta tribuna de PURIQ, apostamos a insertarnos con la sostenibilidad de nuestros colaboradores que envían sus artículos a nuestra revista. El ejercicio de la docencia universitaria considerado con la idea clásica de catedrático a fenecido para dar a lugar a un docente investigador y cumplir lo que establece CONCYTEC en su Reglamento RENACYT: Entre las bases de datos y editoriales que cumplen con un proceso de revisión de pares y otros estándares internacionales se consideran a: SCOPUS, Web of Science, Wiley, IEEE Xplore, Mathematical Reviews, Medline, SPIE digital Library, Springer, McGraw-Hill, Taylor \& Francis Group, EconLit, ProQuest, Bentham Science, Scielo, DOAJ, Redalyc, Latindex. (p.8)

Es conveniente señalar que las revistas que se encuentran en la base de datos clasificados por CONCYTEC, transitaron por una serie de etapas para calificarse y 
sostenerse en el tiempo con sus publicaciones seriadas, con evaluaciones por pares. En este marco de la sana competencia y la ciencia universal, invitamos a nuestros colaboradores y lectores a que sigan apostando por nuestro trabajo académico.

\section{REFERENCIAS BIBLIOGRÁFICAS}

El Peruano, (2020). Decreto supremo. Lima: MINEDU. Recuperado de https://busquedas.elperuano.pe/normaslegales/decreto-supremo-queapruebadisposiciones-para-la-implement-decreto-supremo-n-005-2020minedu-1859670$5 /$

Ministerio de Economía y Finanzas, (s/f). Fondo de Desarrollo Socioeconómico de Camisea-FOCAM. Lima: MEF. Recuperado de https://www.mef.gob.pe/ es/transferencias-a-gobierno-nacional-regional-y-locales/base-legal-yaspectosmetodologicos/fondo-de-desarollo-socioeconomico-de-cami sea-focam

CONCYTEC, (2019). Reglamento RENACYT. Lima: CONCYTEC. Recuperado de https://portal.concytec.gob.pe/images/renacyt/reglamento_renacyt_ version_final.pdf

\section{CITAR COMO:}

$\begin{aligned} & \text { Gutiérrez Gómez, E. } \\ & \text { https://doi.org/10.37073/puriq.2.1.72 }\end{aligned}$
(2020). Publicaciones

